Francisco Zapata Lillo

\title{
Paul Hazard
}

(Presentación del caledráfico de la Sorbonne al iniciar su curso sobre el Romanticismo en la Universidad de Chile).

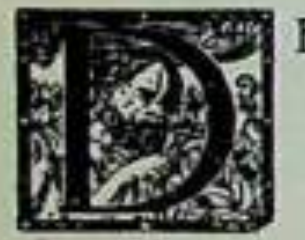

ESDE que la Universidad de Chile cobra nuevo impulso y se renueva al contacto de la mágica varilla que su actual Rector ha recibido del Ideal. un viento de alegria y de esperanza ha soplado sobre la frente de los que piensan y sienten.

En esta transmufación de valores, gran parte loca a la edulce Francia, de Rolando, que nos ha enviado sucesivamente a sus mejores y más sabios hijos, a Widal. a Dumas, a Fougères, a Rey, y que hoy nos envia a $M$. Paul Hazard. en cruzada de ciencia, de verdad, de luz y de latinidad.

La prensa ha abundado ya en elogiosos conceptos para definir la hermosa carrera de uno de los más sabios profesores de la Sorbona y de uno de los más entusiastas latinistas, pues no sólo es $M$. Hazard representante conspicuo del nítido genio francés, sino que es, casi al igual de Ferrero. uno de los más preclaros ingenios de esa raza latina que ha dado al mundo sus ideas generales y sus verdaderos idea. les de humanidad, de amor y de desinterés.

No llega en mala hora el señor Hazard a hablarnos de Chateaubriand. de Lamartine y del Romanticismo, y a aplicar delante de nuestros estudiantes el riguroso método cientifico de las explicaciones de textos. Nuestra juventud artistica y cientifica necesita disciplinar su inspiración y sus estudios. Los escritores y artistas de la nueva generación. de un valor literario y artistico indiscutible y de una imaginación sensifiva potente, necesitan sin embargo, una disciplina rigurosa. Sin método. sin orden. sin plan. los esfuerzos artisticos se pierden y las mismas escuelas (hoy numerosas) mueren. No nos faltan temperamentos; los hay en Chile de sobra, en cualquiera de las bellas artes y aun en las ciencias: los tenemos talvez superiores a otros pucblos; lo que nos falta es concierto, estudio de los grandes maestros. concepción clara de nuestro rol sud-americano y chileno: métodos de trabajo. Necesitamos canalizar los esfuerzos artísticos para crear nuestra verdadera literatura y arte, y hasta ciencia nacionales. Nuestra crítica misma, en general, carece de la flexibilidad necesaria para marcar rumbos y hacer provechosa su enseñanza. 
Rey explicó el año pasado el Método de Decartes y puso de relieve lo que puede la duda, el análisis y la sintesis en filosolia y ciencias. El señor Hazard, al explicarnos los secretos de plan, composición y métodos de algunos de los grandes románticos franceses, nos mostrará los peligros de la imaginación impaciente y desbordada. y las ventajas del genio disciplinado y paciente. ¿No es justamente el gran poeta del mundo, $V$. Hugo, el que dijo: el genio es una larga paciencia.? ¿Y qué monumento más grande levantado a la ciencia que el de ese francés. ejemplo único en el mundo, de ese Fabre, que vivió 60 años inclinado sobre los insectos para estudiar sus costumbres y abrir nuevos rumbos a la filosofia y a la ciencia?

$\mathrm{Y}$ nosotros los maestros, los que trasmitimos la verdad. ¿cuánto no ganaremos con oir a uno de estos hombres franceses cuyas palabras son luz que penetra el interior de las ideas y cuya sabiduria es hecha de claridad, de armonia y de medida?

Conozcamos, entonces, aunque sea rápidamente, al hombre que por espacio de tres meses va a ser nuestro maestro.

A formar el alma cientifica, entusiasta, vibrante y clara del scñor Hazard, han contribuido esos dos grandes profesores que son hoy gloria del mundo latino: Lanson, que fué también maestro de disciplinas francesas del infortunado Nicolás II de Rusia. y Bédier. que acaba de probar que las Canciones de Gesta no tienen nada de germánico, y son sólo poemas literarios, fabricados por los juglares con la colaboración de clérigos y monjes, para retener alrededor de los santuarios de la Edad Media, a los peregrinos que, hacia el año mil y después, iban a los lugares sagrados a hacer votos de religiosidad o de enmienda.

Recuerdo particularmente a estos dos grandes maestros, porque también to fueron mios en los dias maravillosos de mi juventud. Y. si de mi al señor Hazard hay la distancia que hay de un insignificante arbusto a un majestuoso roble. ¿qué culpa tiene el arbusto de recordar que bebió la misma savia generosa que alimentó al robusto roble?

Aparte de la sabiduria de aquellos grandes maestros, tiene también el señor Hazard (como todos los sabios franceses. por otra parte), la modestia, que es la marca exterior más hermosa de la belleza y de la sabiduria.

El señor Hazard oyó las lecciones de Lanson y de Bédier en los Cursos cerrados de la Escuela Normal Superior. esa sin igual Escuela Normal donde se han formado los investigadores más grandes de la Francia. de donde salieron. entre muchos otros: Michelet, y Faguet. para no nombrar sino al poeta de la Historia y al maestro querido que lué durante muchos años el rregalón. de los estudiantes de la Sorbona de mi tiempo, y que, según la alta critica, es el hombre que ha removida más ideas en los últimos sesenta años.

Hoy dia, después de haber ascendido por grados. como los que suben honradamente a las cumbres de los honores, el señor Hazard es macstro de Conferencias en la Sorbona. 
IAhl la Sorbona, da cabeza. .el cerebro, como deciamos cuando éramos alumnos de ella y como creo que aun se sigue diciendo hoy; la Sorbona, donde todo es majestuosamente bello. Allí es donde está el Gran Anfiteatro con el Bosque sagrado de Puvis de Chavanes, que es un himno de colores sobrios y de formas sencillas a la raza latina. Ese anfiteatro en 1905 repercutió con los vivas de 5.000 espectadores que hacian una apoteosis de Cervantes en el Centenario de don Quijote. Alli, en la Sorbona, está también ese cuadrante solar que nos hace reflexionar sobre la brevedad de nuestro viaje terreno. marcando las horas de nuestra vida con su sombra:

Sicut umbra diei nostri.

.Asi pasa la sombra de nuestros dias....

Porque vuestra Sorbona, señor Hazard. no sólo es el alma mater de la Francia intelectual; es también el alma mater de toda la latinidad. de esa latinidad que habéis servido y continuáis sirviendo con vuestra ciencia y vuestro preclaro ingenio. Creo que ha de llegar el día en que nuestros alumnos serán enviados por centenares a beber el agua cristalina de ese purisimo manantial.

He dicho que el señor Hazard tiene la modestia de los sabios franceses. Cierto es que a los dos minutos de conversación con él. estalla a través de su palabra clara. su nativa agilidad de pensamiento. su mágica facilidad de expresión. su ingenio sutil y espontáneo. que lo relaciona con los más sobresalientes ingenios franceses, y su profundidad cientifica, que va hasta la intensidad de un mar herido por la luz del sol meridiano, sin llegar nunca hasta lo turbio y revuelto de los arroyos turbulentos.

$\mathrm{Y}$ esa agilidad, y ese ingenio, os están demostrando que estáis delante de un representanfe de esa aristocracia intelectual que se formó de la fusión de las más grandes cualidades imaginativas y humanas de los Celtas, y de las más puras modalidades del cerebro latino.

Ese cúmulo de cualidades de su raza, donde las oposiciones se equilibran. el señor Hazard las derrama en sus libros a manos llenas: por sus frutos los conoceréis, dice la Biblia.

Su tesis o memoria para obtener el Doctorado en Letras, versa sobre la -Revolución Francesa y las Letras Italianas. Ese libro. aparte de ser un gran esfuerzo de erudición. es la primera piedra puesta al edificio del estudio del renacimiento literario que causó la Gran Revolución en todas las naciones donde los ejércitos del 89 llevaron, con la idea de libertad, el soplo vital de las nacionalidades nuevas. Brunot, el Decano de la Facultad de Letras de París, ha dicho que este libro vino a renovar la ciencia filológica y literaria, señalando nuevos caminos a la investigación.

Cuando el señor Hazard conozea las obras de Lastarria y vea la influencia que la Revolución tuvo en el despertar de nuestro pais y en el Romanticismo 
chileno, verá que su teoria va aun más lejos de lo que él probablemente se imaginó.

En su .Leopardi, el señor Hazard se revela uno de los más inteligentes (si no el más inteligente) conocedor de la literatura italiana, y, sobre todo, de la influencia que el genio doloroso, triste, contradictorio, pero siempre patriota y grande del inmortal autor italiano, luvo sobre la literatura europea. Muestra la poca influencia que Leopardi recibió de las literafuras inglesa, alemana y francesa: señala sus expresiones duras sobre la lengua francesa, expresiones que el señor Hazard explica como deformación del patriotismo, indica la influencia que Leopardi tuvo en algunas literaturas, especialmente en algunos poetas ingleses, y termina colocando a Leopardi entre elos grandes clásicos europeos.:

La erudición del señor Hazard se muestra asimismo profunda en Le Journal de Ginguené. Tamoso literato que vivió de 1748 a 1816.

Bastaria el enunciado de los libros anteriores para mosfrar el servicio que el señor Hazard ha hecho a la alta critica y a la ciencia literaria, impulsándolas a buscar nuevos rumbos en la literatura comparada. Pero. no contento aún con dar vida a las ideas, quiere llevar esas ideas a la práctica. y se pone a la obra, creando ese verdadero monumento de literatura comparada que es la revista que en compañía del señor Baldensperger, publica el señor Hazard desde hace ya cuatro años. Enunciar sólo algunos títulos del sumario del último número bastará para apreciar la preciosa obra emprendida. Hèlos aquí: enfluencia Musulmana en la Divina Comediar. - Michelet en Inglaterra. . Francisco Bertaut y las concepciones dramáticas de Calderón,. - Los idilios de Gessner (poeta suizo), y el ideal pastoral en el preromanticismo europeo. , elc. Se ve que el señor Hazard y sus colaboradores no se detienen ahora en el mundo latino; quieren abrazar en un solo haz las razas del norte y las del sur, y atravesar el Mediterráneo para comprender también las influencias musulmanas en la literatura europea. Es un poderoso esfuerzo de critica; es el ejemplo único de una revisla de critica mundial.

Pero el señor Hazard no se ha detenido aquí. Cree que hay aún otra manera de servir a su patria, y emprende. con Bédier otra inmensa tarea: dar a la Francia una . Hisforia de la Literafura francesa ilustrada.: pero no ilustrada así no mâs. como hay tantas, sino ilustrada con todas las reproducciones en negro y en colores de todas las manifestaciones artísticas que digan relación con la literatura: iconografias de los escritores para ilustrar las biografias y bibliografias, iglesias y vitraux. paisajes y caricaturas, esbozos y croquis, mapas y frontispicios de libros, autógrafos. y cuanto, en una palabra, se halla relacionado con la producción literaria por cualquier motivo. Yo conozco una veintena de . Historias de la literatura francesa. No hay ninguna que represente más erudición y más ciencia.

El pensador no es inferior en el señor Hazard al hombre de ciencia y al critico. En 1912 publicó su bellísimo . Discurso sobre la lengua francesa. que fué premiado por la Academia. 
El Conde Rivarol obtuvo en el siglo XVIII un premio de la Academia de Berlin por haber establecido que la lengua francesa era universal, porque -llevabala honradez en sir.

Después de Rivarol, nadie ha tratado el tema con más cariño, con más verdad. con más ciencia y más profundidad que el señor Hazard. Este discurso del señor Hazard tiene 48 páginas de fexto. Es uno de esos libros de los que Rabelais decía que tienen -substantifica médula.

Hé aqui un ligero resumen:

La lengua francesa era antes de 1789 universal por su claridad y por la hegemonía política de la Francia. La Gran Revolución, al exaltar el principio de nacionalidad, exaltó el amor por las lenguas de cada nación, pues la idea de nación se funde con la idea de lengua nacional. El francés perdió terreno, a pesar de ser la lengua de la libertad. Napoleón quiso imponer el francés por fuerza, lo que contribuyó a su derrota. Después de 1870 . la hegemonía politica se ha perdido, pero nó la fuerza de universalidad de la lengua: son dos cosas distintas. Los griegos impusieron su lengua sin tener hegemonia politica. Hay pueblos modernos que tienen hegemonia y no tienen extensión de su lengua.

En cambio, el francés, si se impone menos politicamente, es más amado y se pide más, a medida que cada nación desea comunicarse con otras naciones, pues cada dia se quiere saber más. El alma se ensancha a medida que retroceden los limites del mundo. El deseo de una lengua universal se presenta: los sabios fabrican el volapuk, la lengua azul, el esperanto, para comunicarse. El francés se aprovecha de haber sido dos veces universal: En la edad media por las Canciones de Gesta, en la edad moderna, por las conquistas anteriores a la Revolución y aun durante ella. Recuérdese que todos los pueblos cantaron la Marsellesa. El francés liene a su favor la fuerza del movimiento comenzado. Es la lengua de una nación hospilalaria ya en tiempo de Strabón. Sus escritores son y deben continuar siendo, a talento igual al talento de los escrifores de otros paises, más sociales y más humanos.

Los escritores franceses dan y deben continuar dando un aspecto de evidencia a las verdades complicadas, expresándolas con claridad. Para mantenerse universal. el francés debe ser el fraductor de la lengua de otros paises. Las reputaciones mundiales deben continuar siendo conocidas por el francés. Ninguna lengua artificial prevalecerá contra el francés, sicmpre que éste se mantenga libre de vulgarismos y la reforma ortográfica no haga perder el valor etimológico, que indica la significación. Evifese el desórden y evítese la crisis de la despoblación. y la expansión del francés se hará naturalmente.

De un pensador es también, al mismo tiempo que de un crítico. su último artículo publicado en el número del 1: de Abril de 1924 de la -Revista de Ambos Mundos, sobre la novela. mezcla de voluptuosidad y religión, - Manon Lescaut., del Abate Prévost. El señor Hazard estudia a los cuatro personajes más importantes de la obra: prueba con variadas citas que el Abate Prévost era enemigo de los Jesuitas y partidario de los Jansenistas; y a pesar de haber borrado el Abate Prévost en la edición de 1753 la palabra -gracia. que figuraba en la edición de 1731. (lo que indica claramente que Des Grieux se había convertido al fin de su vida por obra de 
la gracia y lo que hacía que el sentido jansenista de la obra fuera claro); a pesar de haber agregado indicaciones en la Edición de 1753 que manifestaban el deseo del Abate Prévost de ponerse bien con los Jesuitas, el señor Hazard muestra por otras citas. que la obra fué escrita con espiritu jansenista: pero que ese espiritu fué deformado, pues de la -predestinación. de Pascal, el Abate Prévost retuvo en su libro sólo la impotencia de la voluntad humana para refrenar las pasiones.

Lo más importante en este libro es el esfuerzo histórico y crítico del señor Hazard para fijar el medio apasionado y violento en que se produjo la obra.

El último de los libros de $M$. Hazard es L'Italie Vivante publicado el año pasado. Es una exposición hecha según las ideas expuestas en su Discurso sobre la lengua, y contiene, sobre todo, el desarrollo en Italia del facismo en contra del socialismo fracasado.

El sociólogo profeta. el conocedor amplísimo de la Italia moderna regenerada y prolifica, el amigo sincero de la Peninsula, el conocedor de hombres, y. sobre todo. el artista del estilo, aparecen aquí mejor que en ningún otro libro del señor Hazard.

Sobre todo el estilo. Hay paisajes en esta obra, hay tipos. hay descripciones. hay estudios, que bastarian a la gloria del señor Hazard. Está escrita en forma de dierio.

No puedo resistir, antes de terminar, al deseo de presentaros un trozo de ese diario, para que juzguéis vosotros mismos. Es un estado de alma en un cuadro italiano. Es la explicación de la preferencia del señor Hazard por los grandes artistas, Chateaubriand y Lamartine, pues los grandes artistas sōlo pueden ser criticados, estudiados y amados por otros artistas. Para mí, ese trozo es un modelo que debiera figurar en una Antologia. Hélo aquí:

\section{Brescia, 18 de Octubre de 1921.}

- Como en compañía de algunos viajeros atrasados, en la terraza de un restaurant que da a la plaza de la estación de Brescia. ¿Habéis experimentado alguna vez, de viaje, solos, al terminar el dia, esta extraña expresión de angustia?... Hay en ella una mezcla de cansancio y de nostalgia, un gran disgusto de todas las cosas creadas. Una melancolía infantil os invade poco a poco y se cambia en tristeza profunda; como si alguna hada maléfica volara en torno vuestro. la escena, los personajes, todo parece banal y miserable; se rebela uno hasta contra la caricia de la dulce noche de otoño que os circunda: se cree sentir ya aproximarse el invierno. La comida es detestable. ¿Para qué comer? El vino es pésimo. ¿Para qué beber? Se está mal aqui, se estaria peor en cualquiera otra parte, si cambiáramos de lugar. Un malestar análogo al vuestro parece reinar alrededor de vosotros. Los viajeros están irascibles, los mozos soñolientos toman aires de desdén. Los trenes que llegan con gran ruido. gruñen y silban con maldad. El alma de niño que persiste en cada 
uno de nosotros se emociona y se desespera. Se querría que el viaje estuviera terminado ya: y también terminado este otro viaje mucho más largo, el viaje de la vida. Tres músicos ambulantes se instalan sin apresurarse delante de nuestra terraza iluminada. Tienen aires de grandes señores que quieren con mucho gusto hacerse oír del vulgo: pero. para su propio placer. Afinan sus instrumentos y se ponen a tocar. OOh. maravilloso poder de la música! Todo cambia desde sus primeros acordes. Nos encadenan a su ritmo, nos arrastran con sus sonidos. No somos ya dueños de nosotros mismos: los seguimos a las regiones fabulosas en que reinan la medida y el número: el milagro se opera; y ese milagro nos encanta y nos transporta. Los que comían empiezan a marcar el ritmo de la música. los mozos, alegres ahora. tatarean: los transeuntes. (hace poco sombras, sospechosas, que se escondian tras los árboles). se aproximan y se hacen más humanos y sociables. La noche no es ya hostil. Y vemos ahora que el cielo estaba sembrado de estrellas. El alma del viajero se apacigua y se sorprende de una debilidad que ya no experimenta.

De todos los instrumentos, el violín solo conoce el secreto de penetrar hasta el fondo de nuestro ser. $i \mathrm{Ay}$ ! el violin que tocaba interrumpió su canto divino. Los músicos arreglan sus instrumentos y piden su óbolo ¿Con qué precio no pagará el más avaro esta tregua a su dolor. cuyo efecto persiste después de la partida de los músicos, como si el aire estuviera aún lleno de sonidos musicales y bienhechores?.

He tratado de analizar sucintamente al critico, al hombre de ciencia, al pensador $y$ al artista del estilo.

Pero debo agregar una palabra más. Hay en los escritos del Sr. Hazard, algo que lo hace tan genuinamente francés, que no es posible pasar ese algo en silencio.

Desde los Fabliaux hasta Anatole France, pasando por el Romance del Zorro. por Ruteboeuf, Marot, Rabelais, Molière, La Bruyère, Voltaire, Chamfort, Rivarol, y Faguet, el ingenio francés, la gracia francesa, eso que no se puede definir de otra manera que como el producto de una sensibilidad aguda que descubre fácilmente relaciones entre las ideas, que juega con ellas y que las pone en armonía o en contraste, ese -desco de agradar al enseñar, como dice Fouillée. es tan caracteristico de la raza, que el Sr. Hazard no podria escapar a él y es uno de los motivos por qué se le lee con placer. con verdadero deleite.

En el Sr. Hazard, que es un latino de la pura cepa. que habla el italiano con toda gracia y soltura, y que conoce bien el castellano, se hace aún más notable esta gracia francesa. en cuanto ella permanece en su cerebro perfectamente separada del ingenio italiano o castellano. Hé aquí algunos ejemplos:

Hablando de los socialistas y de las doctrinas económicas de Karl Marx, en derrota y medio agonizantes en Italia. dice el Sr. Hazard que penetró a la sala donde se celebraba un meeting socialista y que vió entre dos banderas rojas el busto de Karl Marx tan blanco y tan ladeado que tenia el aspecto de un enfermo que se inclinaba sobre su almohada, ya agonizante... 
Yo quiero creer que hay una relación estrecha entre la enfermedad de Karl Marx y la derrota de sus teorias económicas.

En otra página de su libro sobre la Italia, nos cuenta el Sr. Hazard que durante una excelente comida, se habló de política socialista, facista y popularista y que después de varias personas, tomó la palabra un abate que habló largamente. mientras el Sr. Hazard espiaba el momento de colocar una palabra. El Sr. abate habló largamente y con toda autoridad. Al fin, vino el momento en que se calló. El Sr. Hazard quiso hablar; pero el señor abate se bebió apresuradamente un buen vaso de vino de Frascati y continuó hablando con la garganta ya refrescada. Yo pensé, al leer esto, en La Bruyère. en el retrato del Glotón, que pica aqui y pica allá, en la mesa, -maneja, las viandas. como dice La Bruyère, saca el mondadientes, se limpia, y comienza a comer de nuevo...

Este ingenio suave, esta media sonrisa, no es la única particularidad francesa del estilo del Sr. Hazard. Su forma toma a veces el modelo de las sentencias, que, como dice Diderot, sfijan la verdad en nuestro recuerdo. Hay algunas sentencias del $\mathrm{Sr}$. Hazard que me encantan:

- La Francia debe vivir y no sobrevivir.

Las gentes que hablan con gusto de su honor son las que lo sienten desfallecer: hablan de él para estar seguras de que todavia no ha desaparecido completamentes.

- Tener miedo de la muerte es ya comenzar a morir.

Señoras, señores.

Tal es, intelectualmente. el gran profesor que está delante de vosotros y que juzgaréis pronto vosotros mismos.

M. Hazard,

Au nom de l'Université du Chili. je vous présente les respectueux hommages de notre bienvenue.

Daignez les recevoir en compagnie de Mme. Daul Hazard. Dans ce siècle de féminisme il sied de ne pas séparer de notre respect et de notre amitié, la charmante dame, qui à travers les mers et les montagnes, accompagne son mari dans la course à l'idéal, remplissant les devoirs que la Nature lui a dévolus.

Nous allons vous entendre, que dis-je! vous écouter. Religieusement. Les gens cultivés qui vous applaudiront connaissent, peut-être, cette constatation de Bismark: son aime la Frances. En tout cas, connaissent-ils mieux cette pensée d'un Anglais, que Hugo a répétée après lui: stout homme culte a deux patries: la sienne et la France. .

FRANCISCO ZAPATA LILLO. 